\title{
Metathesis Depolymerization for Removable Surfactant Templates
}

Timothy M. Long, ${ }^{1}$ Blake A. Simmons, ${ }^{2}$ James R. McElhanon, ${ }^{2}$ Steve R. Kline, ${ }^{3}$ David R. Wheeler, ${ }^{4}$ Douglas A. Loy, ${ }^{5}$ Kamyar Rahimian, ${ }^{4}$ Thomas Zifer ${ }^{2}$ and Gregory M. Jamison $^{* 1}$

${ }^{1}$ Chemical Synthesis and Nanomaterials Department, Sandia National Laboratories, Albuquerque, NM 87185.

${ }^{2}$ Materials Chemistry Department, Sandia National Laboratories, Livermore, CA 94551.

${ }^{3}$ NIST Center for Neutron Research, National Institute of Standards and Technology, Gaithersburg, MD 20899.

${ }^{4}$ Micro-Total-Analytical Systems Department, Sandia National Laboratories, Albuquerque, NM 87185.

${ }^{5}$ Polymers and Coatings Group, MS E549, Los Alamos National Laboratories, Los Alamos, NM 87545.

E-mail: gmjamis@ sandia.gov 


\section{Supplemental Information}

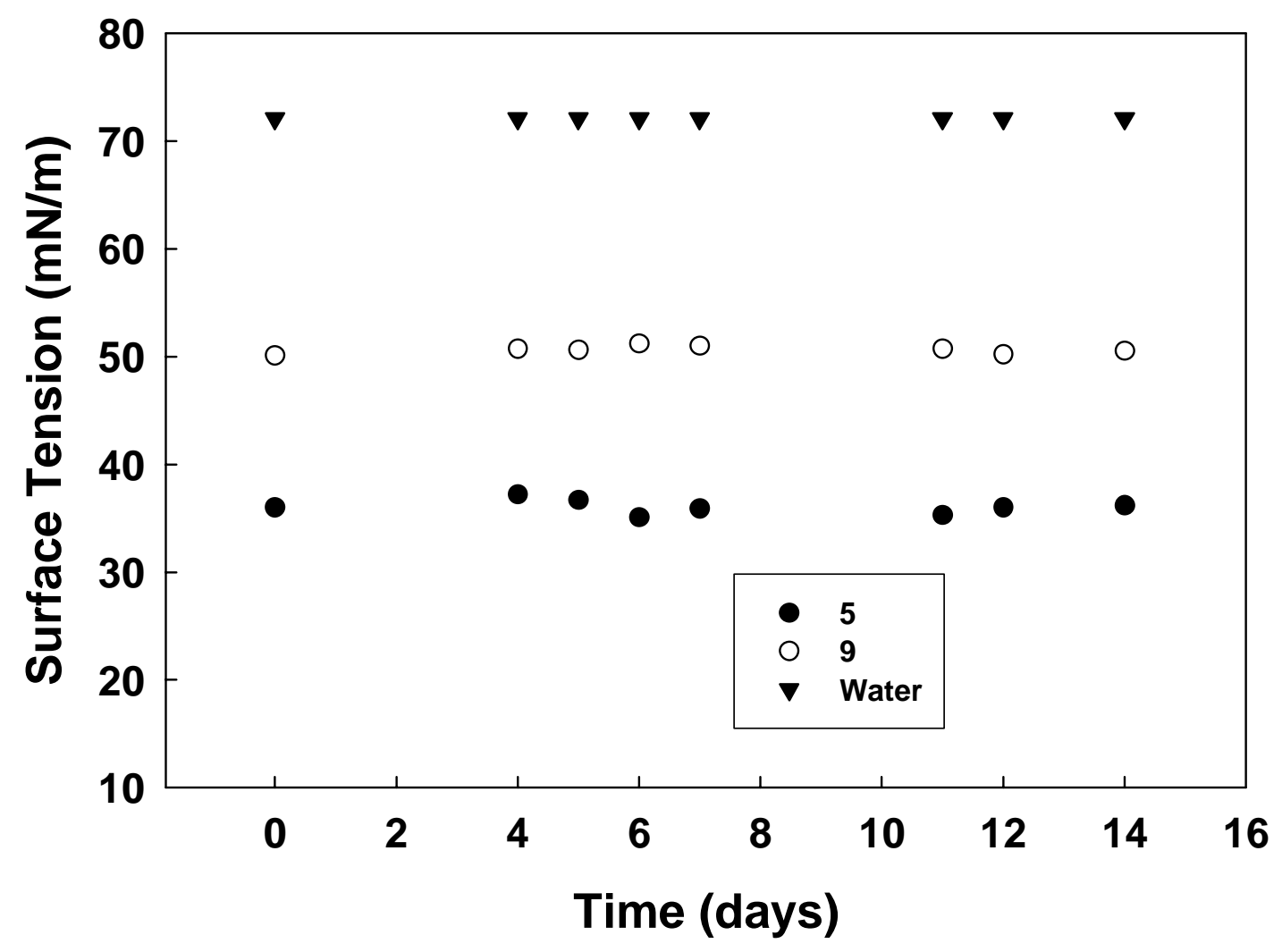

Figure S1. Stability of $10 \mathrm{mM}$ aqueous solutions of $\mathbf{5}$ and $\mathbf{9}$ as a function of time. 


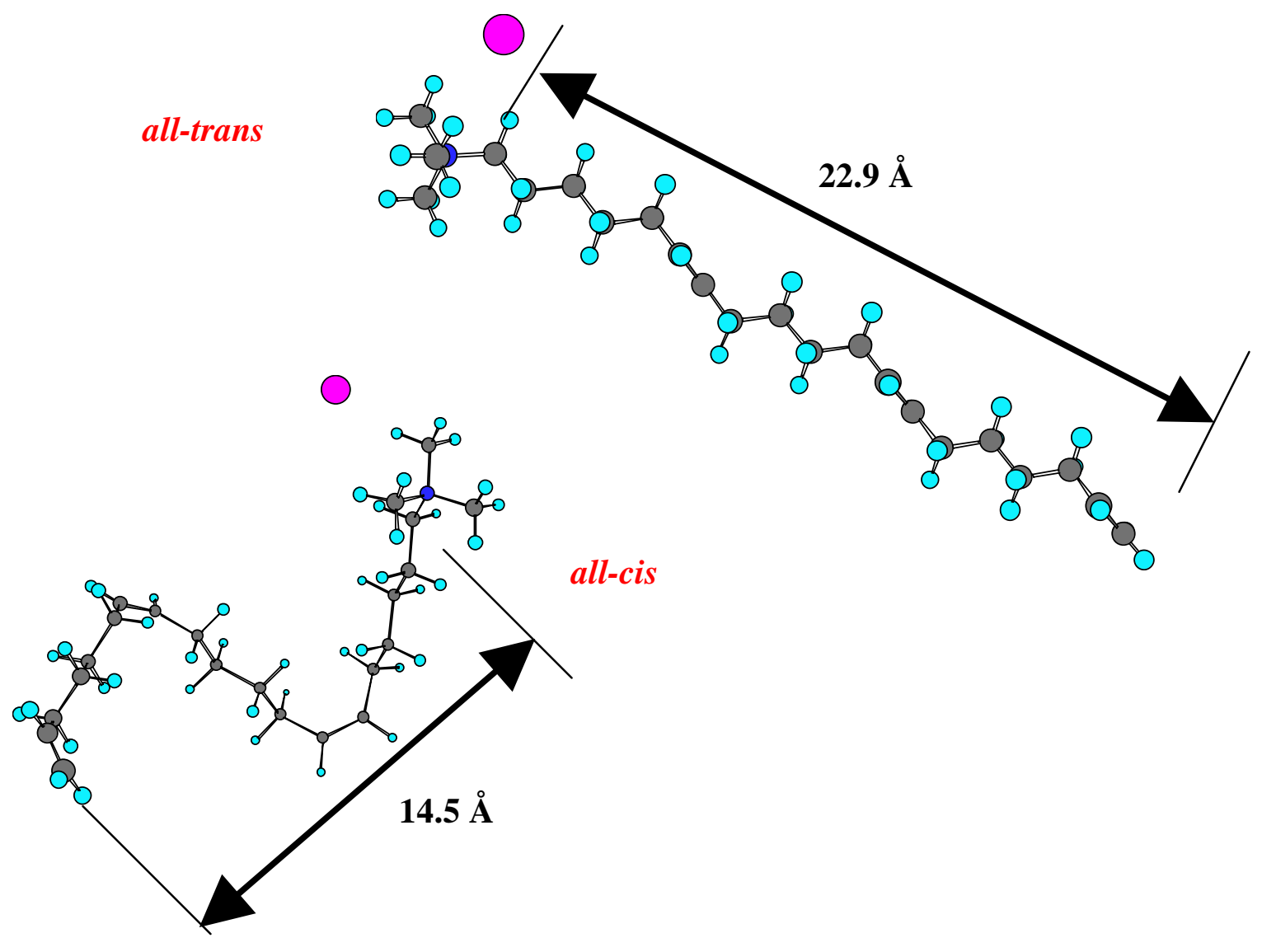

Figure S2. MM2 (Chem 3D, CambridgeSoft, Cambridge, MA) minimized structures for all-trans and all-cis 5 

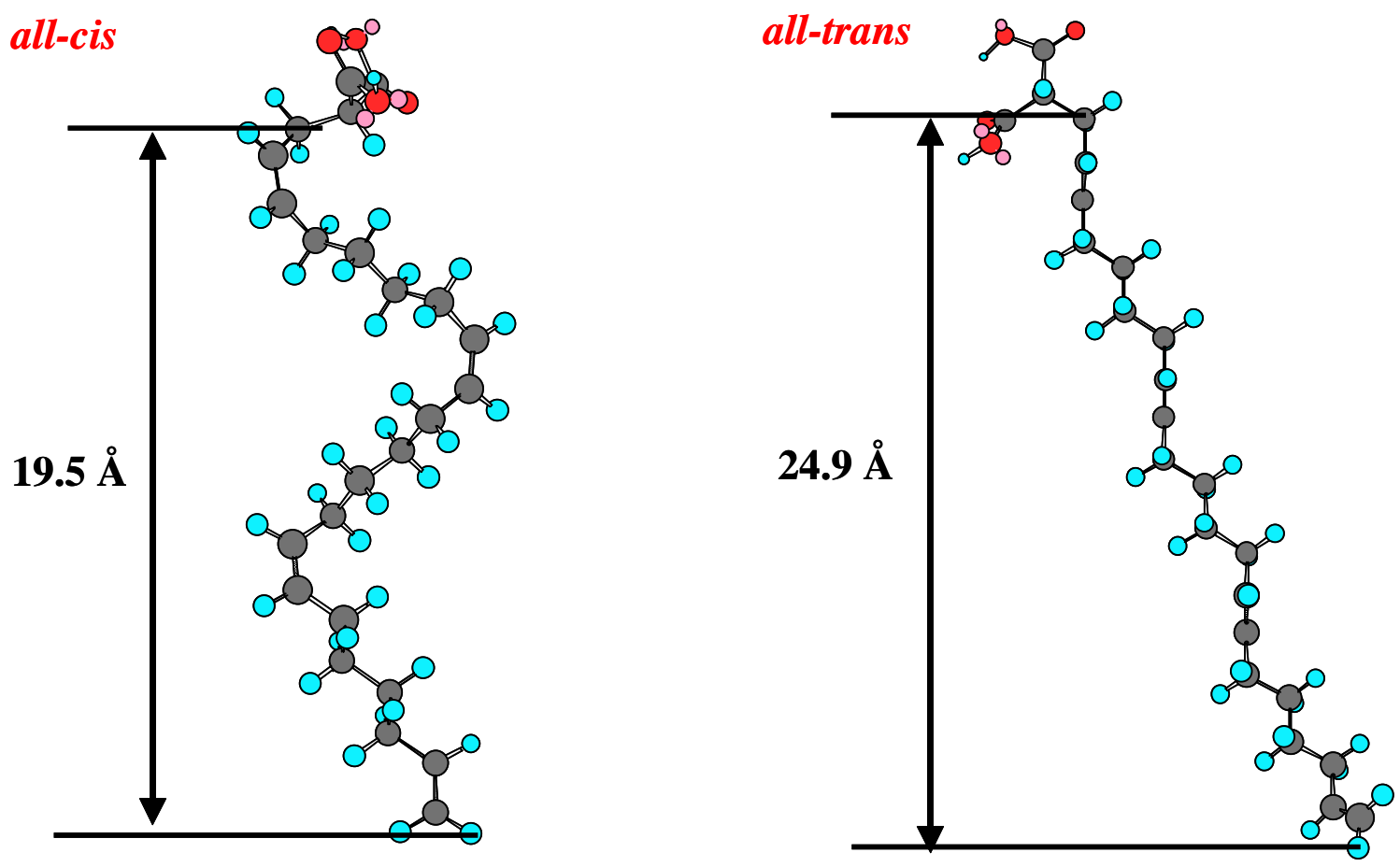

Figure S3. MM2 (Chem 3D, CambridgeSoft, Cambridge, MA) minimized structures for all-trans and all-cis $\mathbf{9}$ 